\title{
Study on the Duration of Market Microstructure Theory
}

\author{
Wei wenjuan ${ }^{1}$ \\ ${ }^{1}$ College of Economics, Ocean University of China, China \\ Correspondence: Wei wenjuan, College of Economics, Ocean University of China, China. \\ E-mail:jingsiboshi@163.com
}

Received: August 20, 2017

Accepted: September 15, 2017

Online Published: September 17, 2017

doi:10.5539/ijbm.v12n10p252

URL: https://doi.org/10.5539/ijbm.v12n10p252

\begin{abstract}
This paper starts from the theory of market microstructure, by researching in the development of market microstructure and the theoretical framework, it is found that the proposed duration model is of great significance to market participants. Therefore, based on the theory of market microstructure, this paper summarizes and analyzes the related theories and applications of ACD model.
\end{abstract}

Keywords: market microstructure theory, duration model, ACD model

\section{Introduction}

Market microstructure theory is a series of studies on the process of asset pricing and price discovery in the financial market from the microscopic perspective. It is also called the microstructure economics of the market, which is an important branch in the field of financial research. A paper published as "transaction cost" by H.Demsetz in the "Economic Journal" lays the theoretical basis of carrying out the related transaction mechanism and asset pricing research in the financial market, opening up the scholars' research on the microstructure theory of the market. O'Hara (1995) argues that market microstructures have a series of effects and impact mechanisms on asset price discovery and pricing in financial products. It can be seen that the developing time of the market microstructure theory is not very long, probably only about 20 years, and due to the rapid development of computer technology in the past 20 years, quantitative transactions become one of the main forms of financial market transactions, As the frequency of transaction increases, people gradually realize that the microstructure of the market, including the setting of the trading system, will have a certain impact on the formation of the price, and the behavior of the market participants under different trading mechanisms has different effects on the formation of the asset price. And the related duration research is the third stage of the development of market microstructure theory, which is a new theoretical model based on the inventory model and the information model, and it reflects the deciding process of market participants to help deepen their understanding of some changes in the transaction process. Therefore, it is not only possible to explore the mechanism of the micro-level factors that affect the pricing process, market structure and market trading mechanism of financial assets from the perspectives of theory and demonstration, but also to further understand the mechanism of micro-level factors based on market microstructure theory And to study the nature and inherent laws of financial markets, so as to make more useful suggestions for financial market participants and market regulators.

\section{Development of Market Microstructure Theory and Its Basic Framework}

Market micro-structure in the narrow sense refers only to the mechanism of price discovery, which is to discuss how pricing is affected by the transaction process in the limited trading system. The theory in the narrow sense is more concerned about the impact on price by the trading system and the trading environment. The generalized market microstructure on the basis of the narrow theoretical basis should include various trading systems and rules in financial markets, such as the liquidation system, the behavior of traders and the transmission mechanism of price. It is not difficult to see that the core of the market microstructure theory is the pricing process of the financial assets in the financial market under the influence of micro-structure, highlighting the important role of financial microstructure.

Market microstructure theory in the narrow sense originated in the late 1960s, when it was really concerned is after the stock market crash in 1987. It first discusses the inventory model, and then studies the pricing process in the financial market from the information theory model to the present stage of duration model. In general, the 
market microstructure consists of the following components: technology, regulation, information, participants and instruments. The "invisible hand" in the financial market organizes those parts and makes a great role. Market efficiency is reflected by the liquidity, volatility, transparency and effectiveness of the market.

In the earliest research of market microstructure theory, the article "transaction costs" proposed that, for the same financial assets, financial markets will appear on the sale of two different quotes, and the final transaction price is to achieve a balanced price in the market, which is the first to introduce the trading system into the pricing of assets to study.

In 1976, Garman officially published the "Market Microstructure (Market Microstructure)" to explore the relationship between the market maker system and the inventory model, trading orders determine the price of assets, and they can be seen as the foundation of the development to promote the microstructure theory.

The second to promote the development of the field is the microstructure theory proposed by O'Hara (1995), including the following parts: first, there are micro-effects of trading mechanisms and market structure on the formation of market price; second, how the price is achieved in the specific trading rules; third, the outcome of the transaction is whether the market optimize the allocation of resources.

Madhavan (2000) gives the content of the market microstructure research focused on how the investor's needs affect the market price and the volume of the deal. The core of the market microstructure research is the important influence of the firm's unique trading mechanism on the securities price. The author thinks that the indicators that describe the market behavior result are market liquidity, stability and information validity. Under the different market structure and information structure, the influence of different traders' behavior and transaction rules on the nature of securities price, thus making the research on the microcosmic theory of market structure transfer from theoretical research to empirical and experimental research. Biais, Glosten and Spatt (2005) summarize the theoretical and empirical and policy implications of the market microstructure using a comprehensive model. Some researchers have made a detailed study of some aspects of the market microstructure theory, such as Harris (1999), Comerton-Ford and Rydge (2004), which provide a general overview of the trading system and the organizational structure of the market.

The research on the empirical and experimental aspects of market microstructure is embodied in the study of the micro-influence of the bid-ask spread and the trading system on the formation of market price. According to the combing of the known literature, the empirical study of the bid-ask spread is mostly carried out around the cost, which can be divided into the following parts: instruction flow processing cost, inventory cost and information cost.

For the study of instruction costs, Roll (1984) proposed the use of only the transaction price data to estimate the cost of implementation, but the method can be regarded as inventory costs for low-frequency data items. In the study of the inventory model, Ho and Macris (1984) found that inventory affects market quotations, and inventory is negatively correlated with the offer. In the study of the information cost, Glosten and Harris (1988) were the earliest to find that information asymmetry caused the inverse selection cost, which is called the information cost. They break down the bid-ask spread into two parts, one part is the information cost, the other part is the residual and can be regarded as inventory costs. Unlike Ho and Macris, the transaction data they use does not indicate the direction of the sale. Some of the latest empirical studies show that the impact of information costs on the bid-ask spreads is increasing with the increase in the size of the stock, which is not significant in small-cap stocks.

\section{The Theory Related to Duration Models}

\subsection{The Basic Theory of Duration Model}

In the traditional research, most of the research on financial microstructure is the use of low-frequency financial data, but with the computer technology reform and the extensive application of large data, low-frequency transactions are no longer meet the real market conditions - market traders tend to gain benefit in the small price changes. On the other hand, artificially dividing the transaction interval into low frequency will also lose a lot of volatility information of days, the use of high-frequency data to study the market microstructure can better reflect the nature of market changes. At this level, high frequency data such as transaction by transaction data or tick by tick data are widely used in the theory and demonstration of microstructure of financial markets.

The empirical results show that compared with the low-frequency data, the application of high-frequency data can further study the characteristics of the microstructure of the market and its inherent changes, and fully understand the nature of influence of the financial market organizational structure and trading system on the market financial asset pricing. In the study of high-frequency data, the duration of the transaction or price is also 
important in addition to the amount of market price, market rate of return, and trading volume that characterize market changes. A transaction or the duration of price is a connotation of the so-called duration, which, to a certain extent, reflects the decision-making process of the market trader and contains certain market information. According to Engle (2002) 's point of view, it is not difficult to see that the price is subject to the impact of new information to adjust, in which the trading mechanism and market structure will play a role.

In the field of finance, the duration worthwhile is the interval between two transactions achieved, also known as the transaction interval or duration. The duration disappearance is an important variable to characterize the change of the market, and it is also an important signal to reflect the decision-making process of the market trader to achieve the final price. It will help to study the pricing process of the microstructure of the financial market deeply. The study shows that the relationship between the length of the duration and the market includes the following parts: First, the duration represents the frequency of market transactions, the longer the duration, the smaller the number of market transactions, the less frequent transactions, and vice versa; Second, the length of the duration of the market also represents the strength of the market, the shorter the duration, the greater the market strength; Third, the duration represents the market liquidity, and they are related. On the other hand, it plays a very important role in the market price discovery process, indicating that the new transaction is reached for the microscopic effect of the market information on price formation.

Duration includes price duration, transaction duration, maturity period, etc., which represent the price fluctuations, transaction density and transaction frequency and intensity. Because of the existence of transaction costs, compared with other forms of duration, researchers are more concerned about price duration. In the duration study, it is often noted that its important feature is whether the data interval rules. As we all know, the traditional econometrics model is based on the same interval data to model, but it will not only lose a lot of the information of days, but also is inconsistent with the actual financial market, so interval modeling is necessary for the unequal transaction .

\subsection{ACD Model}

Engle (1997) first proposed an ACD model for modeling unequal event intervals. The core idea of the ACD model is to establish a time series model to characterize the time of the change of the market characteristic variables. To predict the strength of the transaction process to test the quality and efficiency of the market is a very good application of the microstructure theory of the financial market. This model makes a further analysis of the microstructure of the financial market by using the transaction arrival time and the renewal time of the traded price, which becomes one of the mainstream models to study the unequal interval.

Due to the large theoretical system of financial market microstructure, this paper only studies the impact of information contained in the duration on the behavior of market participants. For high-frequency data tends to have clustering characteristics, and the price changes in the time interval also presents such a feature that a short time interval is often followed by a short time interval, a long time interval often followed by a long time interval. Therefore, it is necessary to test the conclusion that the time interval has a significant correlation if it has a significant correlation, then we can judge the existence of clustering characteristics. The main method is to establish the ACD model for the duration of the time series after the seasoning process. It is possible to judge whether the duration has the characteristics of clustering by estimating the parameters in the model.

The basic idea of the ACD model is derived from the GARCH idea, that is, the autoregressive period. Let $X_{i}$ be the financial time series after the adjustment of the day effect, the experimental results show that $\operatorname{ACD}(1,1)$ can be used to fit the price sequence. The most basic ACD model is the most representative, and it is the most widely used in empirical research. Since ACD $(1,1)$ is linear, it must satisfy the following two conditions: the first is that the required coefficient is a positive number, and then the adjustment process based on the most recent expected value is easier to model in a non-linear form.

The most basic expression for the duration is: $\mathcal{X}_{i}=\psi_{i} \varepsilon_{i}$

$\psi_{i}=E\left(X_{i} \mid \tau_{i-1}\right) ; \tau_{i-1}$ is the information set at time $t_{i-1}$, the past information is affected by $\psi_{i}$, and $\psi_{i}$ is the past or a conditional expectation of a long term. $\varepsilon_{i}$ is an independent isomorphic time series with a specified distribution feature.

Depending on the form of the function, the following two types of models can be extended:

Engle and Russell (1998) proposed the LINEAR-ACD model as follows

$$
\psi_{i}=\omega+\alpha x_{i-1}+\beta \psi_{i-1}
$$

So the expression for the ACD morning linear expression therefore 
$\omega>0, \alpha \geq 0, \beta \geq 0, \alpha+\beta<1$.

Bauwens and Giot (2000) proposed the LOG-ACD model:

$$
\ln \psi_{i}=\omega+\alpha \ln \varepsilon_{i-1}+\beta \ln \psi_{i-1}
$$

Because the model is not a nonlinear model, thus avoiding the restrictions of coefficient to the model for more convenient to use.

The above two models are the linear ACD model and the nonlinear ACD model. The non-linear model also includes the following two kinds of deformation:

Dufour and Engle (2000) proposed BOX-COX-ACD model:

$$
\ln \psi_{i}=\omega+\alpha \varepsilon_{i-1}^{\lambda}+\beta \ln \psi_{i-1}
$$

It is not difficult to find that when $\lambda \rightarrow 0$, BOX-COX-ACD model is LOG-ACD model.

Dufour and Engle (2000) proposed the EX-ACD model:

$$
\ln \psi_{i}=\omega+\alpha \varepsilon_{i-1}+\theta\left|\varepsilon_{i-1}-1\right|+\beta \ln \psi_{i-1}
$$

The model is a well-known index ACD model that can be used to describe asymmetric effects.

\section{Application of Duration Model in Market Microstructure Theory}

Empirical studies have shown that the duration model can improve the accuracy of asset price volatility forecasts. The combination of ACD model and other models can better analyze the volatility, liquidity and other micro-market characteristic variables of financial market, and can better study the microstructure of financial market, providing more helpful suggestions for market investors. Secondly, according to the existing high-frequency financial data model, it can improve the unreasonable asset pricing model, promote the formation of reasonable pricing of financial products, and help to form a healthy and stable financial market. Finally, the combination of the forecast aimed at the duration by ACD model and intraday market risk management can better monitor market risk and provide investors with a good risk management tool.

It has to be said that the good statistical characteristics of the duration model in the huge theoretical system of all the micro-structures in the market are of great significance to market investors, market organizers and market regulators. And it has a guiding significance for the establishment of organizational structure and trading rules of Chinese futures market and stock market.

\section{References}

Biais, B., Larry, G., \& Chester, S. (2005). Market Microstructure: A Survey of Microstructures, Empirical Results, and Policy Implications. Journal of Financial Markets, 8, 217-264. https://doi.org/10.1016/j.finmar.2004.11.001

Comerton-Ford, C., \& James, R. (2004). A Review of Stock Market Microstructure. Working Paper Supported by Capital Markets CRC Limited. https://doi.org/10.2139/ssrn.710801

Demsetz, H. (1968). The cost of transaction. Quarterly Journal of Economics, 82(1), 33- 53. https://doi.org/10.2307/1882244

Engle, R. F., \& Russell, J. R. (1998). Autoregressive conditional duration a new model for irregularly spaced transaction data. Econometrica, 66, 1127-1162. https://doi.org/10.2307/2999632

Garman, M. B. (1976). Market microstructure. Journal of Economics, 3(3), 257-275. https://doi.org/10.1016/0304-405X(76)90006-4

Glosten, L., \& Harris, L. (1988). Estimating the Com- ponents of the Bid- Ask Spread. Journal of financial Economics, 21, 123-142. https://doi.org/10.1016/0304-405X(88)90034-7

Harris, L. (1999). Trading and Exchanges, Mimeo. Uni- versity of Southern California.

Ho, T., \& Macris, R. (1984). Dealer Bid- Ask Quotes and Transaction Prices: An Empirical Study of some AMEX Options. Journal of Finance, 39, 23-45. https://doi.org/10.1111/j.1540-6261.1984.tb03858.x

Madhavan, A. (2000). Market Microstructure: Survey. Journal of Financial Markets, 3, 205-258. https://doi.org/10.1016/S1386-4181(00)00007-0

O'Hara, M. (1996). MarketMicrostructure Theory. Cambridge,MA: Blackwell Publishers.

Roll, R. (1984). A Simple Implicit Measure of the Ef- fective Bid- Ask Spread. Journal of Finance, 39, 1127-1139. https://doi.org/10.1111/j.1540-6261.1984.tb03897.x 


\section{Copyrights}

Copyright for this article is retained by the author(s), with first publication rights granted to the journal.

This is an open-access article distributed under the terms and conditions of the Creative Commons Attribution license (http://creativecommons.org/licenses/by/4.0/). 